\title{
Hypoglycemic Effect of Electroacupuncture Combined with Antrodia cinnamomea in Dexamethasone-Induced Insulin-Resistant Rats
}

\author{
Unurzul Manlai, $\mathrm{PhD},{ }^{1,2}$ Su-Wei Chang, $\mathrm{PhD},{ }^{2}$ Shih-Chieh Lee, $\mathrm{PhD},{ }^{1,3}$ Wai-Jane Ho, $\mathrm{PhD},{ }^{1,2}$ \\ Tai-Hao Hsu, PhD, ${ }^{1,3}$ Jaug-Geng Lin, MD, PhD, ${ }^{4}$ Chih-Ming Lin, MD, $\mathrm{PhD},{ }^{2,5, *}$ \\ Ying-I Chen, $\mathrm{PhD},{ }^{2, *}$ and Shih-Liang Chang, $\mathrm{MD}, \mathrm{PhD}^{1,2,4, *}$
}

\begin{abstract}
Objective: Antrodia cinnamomea (AC), a medicinal mushroom indigenous to Taiwan, exerts various pharmacologic activities. This study compared and evaluated the hypoglycemic effect of treatment with electroacupuncture (EA) combined with AC in steroid-induced insulin-resistant (SIIR) rats.

Materials and Methods: Rats were divided into saline, EA, AC, AC+EA, and rosiglitazone (TZD) groups. Plasma-glucose levels were measured in serial blood samples and compared before and after treatment in each group. The levels of signaling proteins-glucose transporter 4, (GLUT4), phosphoinositide 3-kinase (PI3-K), and 5' adenosine monophosphate-activated protein kinase (AMPK) — were analyzed by Western blotting to explore their mechanisms of action.

Results: The AC+EA group had reduced plasma-glucose levels at 30 and 60 minutes in SIIR rats, compared to normal rats, and this was better than the EA, AC, and TZD groups at 60 minutes. Furthermore, the signaling protein (GLUT4, PI3-K, and AMPK) levels were increased significantly.

Conclusions: These findings showed improved hypoglycemic activity and insulin resistance after EA combined with AC treatment. Therefore, the combined therapy might be a more-effective method than the individual therapies that elevates the expression of the signal proteins, as observed in this study.
\end{abstract}

Keywords: electroacupuncture, Antrodia cinnamomea, plasma glucose, dexamethasone, insulin, signal transduction proteins

\section{INTRODUCTION}

$\mathbf{S}^{\mathrm{s}}$ EDENTARy LifeStyle AND Overeating can result in an overabundance of glucose and fatty-acid accumulation within the muscles, adipose tissue, and pancreatic cells. Hyperglycemia is a common outcome of uncontrolled diabetes that leads to severe damage in many parts of the body's system over time, especially the nerves and blood vessels. ${ }^{1}$ High doses of glucocorticoid are the most common cause of drug-induced diabetes mellitus. ${ }^{2}$ The pathophysiology of insulin resistance involves a complex network of insulin-signaling pathways. Activation of the inhibitor $\kappa$-B kinase (IKK) pathway increases insulin receptor substrate-1 (IRS-1) serine phosphorylation, leading to suppression of insulin signaling. The suppression of the IKK pathway decreases insulin resistance and ameliorates glucose intolerance, thus, likely activating stress signaling. ${ }^{1}$

\footnotetext{
${ }^{1}$ College of Biotechnology and Bioresources, ${ }^{2}$ Department of Medicinal Botanicals and Health Applications, and ${ }^{3}$ Department of Food Science and Biotechnology, Da-Yeh University, Changhua, Taiwan.

${ }^{4}$ School of Chinese Medicine, China Medical University, Taichung City, Taiwan.

${ }^{5}$ Department of Neurology, Changhua Christian Hospital, Changhua City, Taiwan.

*These authors contributed equally to this article.
} 
A previous study of Antrodia cinnamomea (AC) demonstrated that insulin sensitivity was enhanced with AC, indicating its insulin sensitizer function in insulin-resistant animal models, and an optimal dose for further study was determined. ${ }^{3}$ $\mathrm{AC}$ is a medicinal mushroom indigenous to Taiwan and grows only in the inner cavity of Cinnamomum kanehirae hayata (Lauraceae). Taiwan aborigines commonly use the fruiting body of AC as a folk medicine to promote health and to treat liver disease, drug and food intoxication, diarrhea, and cancer. ${ }^{4}$ Recently, AC has been found to exert a variety of biologic activities, including antioxidant, hypoglycemic, anticancer, ${ }^{5,6}$ liver protective ${ }^{7,8}$ anti-inflammatory, ${ }^{9,10}$ and immune-regulatory effects. ${ }^{11,12}$ In addition, many bioactive components of AC have been identified, such as polysaccharides, terpenoids, benzenoids, and nucleic acids. ${ }^{13}$ The extracts of AC mycelia and its components, such as polysaccharides, anthraquinone, and antrocin B, were found to improve diabetes and dyslipidemia in mice fed a high-fat diet. ${ }^{12,14,15}$

Electroacupuncture (EA) is a modified therapeutic technique for piercing the skin with acupuncture needles while reinforcing them with low-voltage electrical currents. ${ }^{16}$ Hence, the therapeutic effect of EA was investigated for the ability to increase expression of insulin-signaling proteins IRS-1 and glucose transporter 4 (GLUT4) in skeletal muscle, which is consistent with an improvement in steroidinduced insulin-resistant (SIIR) rats. ${ }^{3}$ The insulin receptors, GLUT, and peroxisome proliferator-activated receptors are considered potential targets in the development of new treatment methods for diabetes mellitus. For example, the c-Jun N-terminal kinases (JNK) and IKK pathways are involved in the development of insulin resistance, and these could be therapeutic targets for diabetes. ${ }^{1}$

Therefore, this present study explored the effect of combined EA with AC, compared with single-therapy EA, AC, or rosiglitazone (TZD), on the SIIR rat model, and observed the mechanisms of effects on hyperglycemia through the expression of signal proteins. The EA and AC combination has been suggested as a potential therapy for patients with diabetes mellitus.

\section{MATERIALS AND METHODS}

\section{Preparation of AC Mycelia}

The AC mycelia were cultured in the dark on solid-state cereal medium (provided by author W.-J. H., of Da-Yeh University, Changhua, Taiwan) for $85-90$ days at $21^{\circ} \mathrm{C}-$ $23^{\circ} \mathrm{C}$. The medium was mainly supplemented with yeast extract and glucose. After this, the cultures were harvested, dried, and ground into powder for subsequent experiments. The final yield from the solid-state culture was $\sim 20 \%$ of the original dry weight of the cereal medium. In addition, the powder was mixed with normal saline to produce oral solutions at a concentration of $500 \mathrm{mg} / \mathrm{kg}$ of body weight (BW) and stored at $4^{\circ} \mathrm{C}$ until needed for analysis.

\section{Animal Models}

Wistar rats were purchased from the Bio LASCO Animal Center (Taipei, Taiwan), allowed to acclimatize at the Animal Breeding Center. The rats were housed at $25^{\circ} \mathrm{C} \pm 1{ }^{\circ} \mathrm{C}$ with a relative humidity of $65 \% \pm 5 \%$ in a 12 -hour light/dark cycle with ad libitum access to water and food (general rat chow). The Institutional Animal Care and Use Committees (IACUC), of Da-Yeh University, reviewed the animal research ethics and ethical approval (Number: DYU-100011-R0038) was given.

This study was performed according to previously published research methods. ${ }^{17}$ The SIIR rats were injected intraperitoneally (i.p.) with $1 \mathrm{mg} / \mathrm{kg}$ of dexamethasone daily for 5 days. It was concluded that insulin resistance was successfully induced when the rats' fasting plasma glucose levels were higher than $150 \mathrm{mg} / \mathrm{dL}$. The SIIR rats were fasted before each test and anesthetized with pentobarbital $(40 \mathrm{mg} / \mathrm{kg}$, i.p.), and the experiments were performed at 8:00 AM. $^{3}$

\section{EA Treatment}

The rats in the EA treatment group were administered EA on bilateral Zusanli acupoints (ST 36). The electrical current was provided through Han's acupoint nerve stimulator (Healthtronics, Singapore) with a frequency of $15 \mathrm{~Hz}^{18}$ at a $10 \mathrm{~m} A$-intensity level between 30 and 60 minutes. ${ }^{19}$

\section{Experimental Protocol}

The rats were randomly divided into the following different groups ( $n=6$ per group): (a) saline group: Wistar rats orally administered an equal volume of saline; (b) $\mathrm{AC}$ group: Wistar rats orally administered AC $(500 \mathrm{mg} / \mathrm{kg})$; (c) EA group: Rats administered normal saline injection and given bilateral Zusanli acupoint (ST 36) EA at $15 \mathrm{~Hz} / 10 \mathrm{~mA}$ treatments; (d) AC+EA group (AC+EA): Rats administered AC and EA per the previous schedules; (e) TZD group: Rats orally administered rosiglitazone $(0.1 \mathrm{mg} / \mathrm{kg}) .^{3}$

\section{Assay for the Plasma Glucose Levels}

Plasma glucose levels assays were performed with a commercial enzymatic method using a Glucose HK stable liquid reagent (Randox Laboratories Ltd., Crumlin, UK). The percentage of the hypoglycemic activity was calculated as follows: plasma glucose levels at 0 minutes, then plasma glucose levels at: 
The optimal group dosage for inducing hypoglycemia was determined and used in subsequent experimental procedures.

\section{Enzyme-Linked Immunosorbant Assay of Plasma Insulin Levels and Resistance Test}

We performed enzyme-linked immunosorbent assays (ELISAs) with kits obtained from Mercodia AB (Uppsala, Sweden). First, $25 \mu \mathrm{L}$ of serum and $50 \mu \mathrm{L}$ of conjugate solution was prepared in each measuring tank and shaken for 2 hours at room temperature. Then, the mixed solution was rinsed 5 times with $350 \mu \mathrm{L}$ of buffer, $200 \mu \mathrm{L}$ of peroxidase substrate (3,3',5,5'-tetramethylbenzidine) added, and incubated for 15 minutes at room temperature. Finally, a $50-\mu \mathrm{L}$ solution $\left(1 \mathrm{M} \mathrm{H}_{2} \mathrm{SO}_{4}\right)$ was added to the reaction and shaken for 5 seconds, then measured with a spectrophotometer $(450 \mathrm{~nm})$. The homeostatic model assessment of insulin resistance (HOMA-IR) was calculated using the following formula:

[fasting plasma insulin levels $(\mu \mathrm{U} / \mathrm{mL}) \times$ fasting plasma glucose $(\mathrm{mmol} / \mathrm{L})] / 22.5{ }^{3}$

\section{RESULTS}

\section{Effect of Hypoglycemic Activity in Normal Wistar Rats}

The different treatments in the experiments were compared to the hypoglycemic activity of normal Wistar rats. The hypoglycemic activity of each group at 30 minutes were as follows: saline group $=11.47 \pm 4.89 \%$ (b); AC group $=$ $19.75 \pm 5.46 \%$ (b); EA group $=41.36 \pm 9.25 \%$ (a); AC+EA group $=41.27 \pm 6.71 \%$ (a); and TZD group $=14.92 \pm 3.05 \%$ (b), where a and b represented the statistical markers, $\mathrm{a}>\mathrm{b}$; $P<0.05$. Furthermore, the hypoglycemic activity of each group at 60 minutes was as follows: saline group $=21.56 \pm$ $4.01 \%$ (C); $\mathrm{AC}$ group $=25.25 \pm 3.13 \%$ (C); EA group $=$ $45.68 \pm 9.68 \%$ (B); AC+EA group $=60.35 \pm 5.60 \%$ (A); and TZD group $=20.27 \pm 9.84 \%(C)$, where $A, B$ and $C$ represented the statistical markers, $\mathrm{A}>\mathrm{B}>\mathrm{C} ; P<0.05$. The plasma glucose levels of the normal Wistar rats treated with

\section{Western Blot Analysis}

For Western blotting, anti-phosphoinositide 3-kinase (PI3-K), anti-GLUT4, and 5' adenosine monophosphateactivated protein kinase (AMPK) antibodies were added in a radioimmunoprecipitation assay lysis buffer, and ground using a homogenizer-pending protein extraction. The appropriate concentration of protein was added to reduce sample buffer (glycerol, $\beta$-mercaptoethanol, sodium dodecyl sulfate [SDS], Tris- $\mathrm{HCl}$ ), and boiled to denature at $95^{\circ} \mathrm{C}$ for 15 minutes. A total of $90 \mu \mathrm{g} / \mathrm{mL}$ of protein was separated by $8 \%$ SDS-polyacrylamide gel electrophoresis, and the gel transferred to a polyvinyl fluoride (PVDF) membrane at $4^{\circ} \mathrm{C}$.

The PVDF membrane was then submerged in 5\% nonfat milk to block the nonspecific binding sites in the membrane at $25^{\circ} \mathrm{C}$ for 1 hour. The membrane was incubated overnight with anti-PI3-K, anti-GLUT4, and AMPK antibodies at $4^{\circ} \mathrm{C}$, and washed four times (10 minutes each) with phosphate buffered saline with Tween ${ }^{\circledR}$ detergent buffer after the incubation. Finally, the membranes were incubated with goat antirabbit immunoglobulin G-horseradish peroxidase antibodies at $25^{\circ} \mathrm{C}$ for 1 hour, and specific bands were detected, using an enhanced chemiluminescence kit. The bands were quantified using optical densitometry, while actin bands were used as internal loading controls, and the results were presented as the ratio of signal-to-actin.

\section{Statistical Analysis}

Statistical analysis was performed using a Student's $t$-test or one-way analysis of variance, and the results were presented as the mean \pm standard error for each group. Statistical significance was obtained at a $P$-value $<0.05$.
$\mathrm{EA}$, and $\mathrm{EA}+\mathrm{AC}$, decreased significantly, compared to the saline, AC, and TZD groups, at the 30 and 60 minutes. In particular, the hypoglycemic activity of the combined therapy $(\mathrm{EA}+\mathrm{AC})$ was greater than the signal therapy (EA, AC, TZD) at 60 minutes; $P<0.05$ (Fig. 1).

\section{Effect of Hypoglycemic Activity in SIIR Rats}

In the SIIR group, the hypoglycemic activities at 30 minutes were as follows: saline group $=21.06 \pm 7.87 \%$ (b); $\mathrm{AC}$ group $=28.97 \pm 8.71 \%$ (b); EA group $=51.27 \pm 3.47 \%$

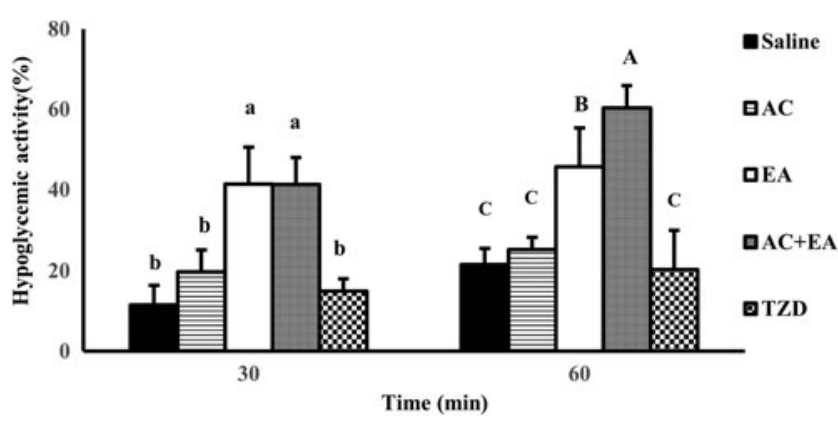

FIG. 1. Hypoglycemic activity of different treatments in Wistar rats. The saline group was administered normal saline. In the Antrodia cinnamomea (AC) group, Wistar rats were administered oral AC extract $(500 \mathrm{mg} / \mathrm{kg})$. The electroacupuncture (EA) group received normal saline and EA at $\mathrm{ST} 36(15 \mathrm{~Hz} / 10 \mathrm{~mA})$. The $\mathrm{AC}+\mathrm{EA}$ group received $\mathrm{AC}$ and $\mathrm{EA}$ as previously scheduled. The TZD (rosiglitazone) group was administered $0.1 \mathrm{mg} / \mathrm{kg}$ of oral rosiglitazone. Statistical analysis was performed using an analysis of variance, $\mathrm{a}>\mathrm{b}>\mathrm{c} ; \mathrm{A}>\mathrm{B}>\mathrm{C} ; P<0.05$. min, minutes. 


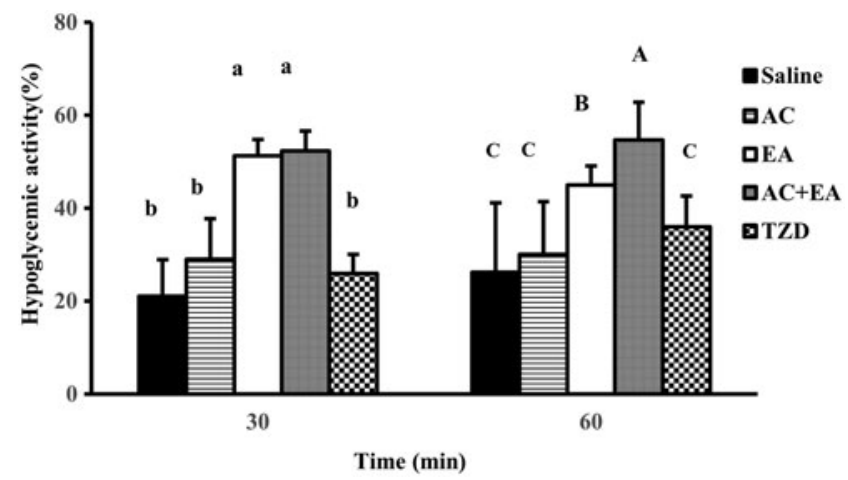

FIG. 2. Hypoglycemic activity of different treatments in steroid-induced insulin-resistant (SIIR) rats. The saline group was administered normal saline. In the Antrodia cinnamomea (AC) group, Wistar rats were administered oral AC extract $(500 \mathrm{mg} / \mathrm{kg})$. The electroacupuncture (EA) group received normal saline and EA at ST $36(15 \mathrm{~Hz} / 10 \mathrm{~mA})$. The $\mathrm{AC}+\mathrm{EA}$ group received $\mathrm{AC}$ and $\mathrm{EA}$ as previously scheduled. The TZD (rosiglitazone) group was administered oral rosiglitazone $(0.1 \mathrm{mg} / \mathrm{kg})$. Statistical analysis was performed using an analysis of variance, $\mathrm{a}>\mathrm{b}>\mathrm{c}$; $\mathrm{A}>\mathrm{B}>\mathrm{C}$; $P<0.05$. min, minutes.

(a); $\mathrm{AC}+\mathrm{EA}$ group $=52.30 \pm 4.25 \%$ (a); and TZD group $=$ $25.96 \pm 4.07 \%$ (b), where a $>$ b; $P<0.05$. Furthermore, the hypoglycemic activities at 60 minutes were as follows: saline group $=26.21 \pm 14.90 \%(\mathrm{C}) ; \mathrm{AC}$ group $=30.06 \pm$ $11.30 \%$ (C); EA group $=44.98 \pm 4.11 \%(B)$; AC+EA group $=$ $54.63 \pm 8.12 \%(\mathrm{~A})$; and TZD group $=36.01 \pm 6.55 \% \quad(\mathrm{C})$, where $\mathrm{A}>\mathrm{B}>\mathrm{C} ; P<0.05$. The plasma glucose levels of SIIR rats treated with $\mathrm{EA}$, and $\mathrm{EA}+\mathrm{AC}$, decreased significantly, compared to the saline, AC, and TZD groups at 30 and 60 minutes. In particular, the hypoglycemic activity of the combined therapy $(\mathrm{EA}+\mathrm{AC})$ was greater than the signal therapy (EA, AC, TZD) at 60 minutes; $P<0.05$ (Fig. 2).

\section{Comparison of Plasma Insulin and HOMA-IR in Normal Wistar Rats}

The plasma insulin levels of normal Wistar rats did not change significantly in each group after 60 minutes. Furthermore, the HOMA-IR index in each group was significantly attenuated at 60 minutes only for the AC, EA, or AC+EA treatments. Specifically, the AC+EA group had more significant change than the saline group; $* P<0.05$ vs 0 minutes according to the Student's $t$-test (Table 1).

\section{Comparison of Plasma Insulin and HOMA-IR in SIIR Rats}

The plasma insulin levels of SIIR rats did not change significantly in each group after 60 minutes, except for in the TZD group. Furthermore, the HOMA-IR index in each group of SIIR rats was significantly attenuated at 30 and 60 minutes, except in the saline group. The drop in percentage at 60 minutes of the AC, EA, AC+EA and TZD groups was more than that observed for the saline group. Specifically, the drop in the percentage of the $\mathrm{AC}+\mathrm{EA}$ group (69\%) was a more significant change than in the saline (13.6\%) group and this was approximately equal to the positive control TZD (61.9\%) group (Table 1).

\section{Impact of Signaling Proteins on SIIR Rats}

After administering different treatments in the SIIR rats, the gastrocnemius muscle was taken, and the insulin-signaling proteins, for example, GLUT-4 (Fig. 3A), were detected by Western blot. Each treatment group (AC, EA, AC+EA, or TZD) had significantly elevated insulin-signaling proteins, compared with the saline group. The level of the signal protein $\mathrm{PI} 3-\mathrm{K}$ is shown in Figure 3B. The AC and AC+EA groups had

Table 1. Changes in Plasma Insulin and HOMA-IR Index

\begin{tabular}{|c|c|c|c|c|c|c|c|c|}
\hline \multirow{2}{*}{\multicolumn{2}{|c|}{$\frac{\text { Group }}{\text { Time (min) }}$}} & \multicolumn{3}{|c|}{ Plasma insulin levels $(\mu \mathrm{g} / \mathrm{mL})$} & \multicolumn{3}{|c|}{ HOMA-IR index } & \multirow{3}{*}{$\frac{0-60 \text { change } \%}{27.3 \pm 1.2, \mathrm{~B}}$} \\
\hline & & \multirow{2}{*}{$\frac{0}{0.27 \pm 0.01}$} & \multirow{2}{*}{$\frac{30}{0.29 \pm 0.08}$} & \multirow{2}{*}{$\begin{array}{c}60 \\
0.25 \pm 0.03\end{array}$} & \multirow{2}{*}{$\begin{array}{c}0 \\
1.86 \pm 0.36\end{array}$} & \multirow{2}{*}{$\frac{30}{1.83 \pm 0.62}$} & \multirow{2}{*}{$\begin{array}{c}60 \\
1.35 \pm 0.28\end{array}$} & \\
\hline Wistar & Saline & & & & & & & \\
\hline & $\mathrm{AC}$ & $0.26 \pm 0.01$ & $0.26 \pm 0.01$ & $0.23 \pm 0.01$ & $1.58 \pm 0.04$ & $1.30 \pm 0.04 *$ & $1.07 \pm 0.03 *$ & $32.4 \pm 4.7, \mathrm{~B}$ \\
\hline & EA & $0.25 \pm 0.01$ & $0.22 \pm 0.00$ & $0.23 \pm 0.01$ & $1.71 \pm 0.05$ & $0.79 \pm 0.01 *$ & $0.68 \pm 0.02 *$ & $69.1 \pm 9.1, \mathrm{~A}$ \\
\hline & $\mathrm{AC}+\mathrm{EA}$ & $0.26 \pm 0.02$ & $0.25 \pm 0.03$ & $0.23 \pm 0.00$ & $1.90 \pm 0.23$ & $1.08 \pm 0.07$ & $0.58 \pm 0.01 *$ & $68.9 \pm 3.5, \mathrm{~A}$ \\
\hline & TZD & $0.54 \pm 0.21$ & $0.35 \pm 0.13$ & $0.27 \pm 0.01$ & $3.48 \pm 0.90$ & $2.21 \pm 1.12$ & $2.21 \pm 0.23$ & $30.1 \pm 4.8, \mathrm{~B}$ \\
\hline \multirow[t]{5}{*}{ SIIR } & Saline & $0.25 \pm 0.01$ & $0.21 \pm 0.00$ & $0.24 \pm 0.02$ & $1.54 \pm 0.14$ & $1.11 \pm 0.04$ & $1.32 \pm 0.05$ & $13.6 \pm 0.7, \mathrm{c}$ \\
\hline & $\mathrm{AC}$ & $0.17 \pm 0.07$ & $0.15 \pm 0.05$ & $0.17 \pm 0.07$ & $1.37 \pm 0.07$ & $0.87 \pm 0.07 *$ & $0.97 \pm 0.07 *$ & $28.5 \pm 1.1, \mathrm{~b}$ \\
\hline & EA & $0.26 \pm 1.40$ & $0.23 \pm 1.41$ & $0.20 \pm 1.05$ & $8.65 \pm 0.01$ & $2.81 \pm 0.01 *$ & $2.49 \pm 0.00 *$ & $59.6 \pm 0.5, \mathrm{a}$ \\
\hline & $\mathrm{AC}+\mathrm{EA}$ & $1.00 \pm 0.28$ & $0.54 \pm 0.7$ & $0.62 \pm 0.29$ & $6.79 \pm 2.16$ & $1.81 \pm 0.15^{*}$ & $1.72 \pm 0.94 *$ & $69.0 \pm 2.3, \mathrm{a}$ \\
\hline & TZD & $0.29 \pm 0.00$ & $0.16 \pm 0.01 *$ & $0.18 \pm 0.00 *$ & $13.50 \pm 0.03$ & $3.14 \pm 0.03 *$ & $3.36 \pm 0.02 *$ & $61.9 \pm 0.1, \mathrm{a}$ \\
\hline
\end{tabular}

Saline group: Wistar rats were administered normal saline orally; AC group: Wistar rats were administered extract of AC (500 mg/kg) orally; EA group: received normal saline and EA $(15 \mathrm{~Hz} / 10 \mathrm{~mA})$ bilateral ST 36 acupoints; AC+EA group: received AC and EA as previously scheduled; TZD group: received orally administered rosiglitazone $(0.1 \mathrm{mg} / \mathrm{kg}) ; * P<0.05$ versus. 0 min per a Student's $t$-test. $0-60$ change $\%$ : $*$ Significant result.

Significant differences were determined by least significant difference post hoc test following an analysis of variance, A $>\mathrm{B}$ or a $>\mathrm{b}>\mathrm{c} ; P<0.05$. HOMA-IR, homeostatic model assessment of insulin resistance; min, minutes; AC, Antrodia cinnamomea; EA, electroacupuncture; TZD, rosiglitazone. 

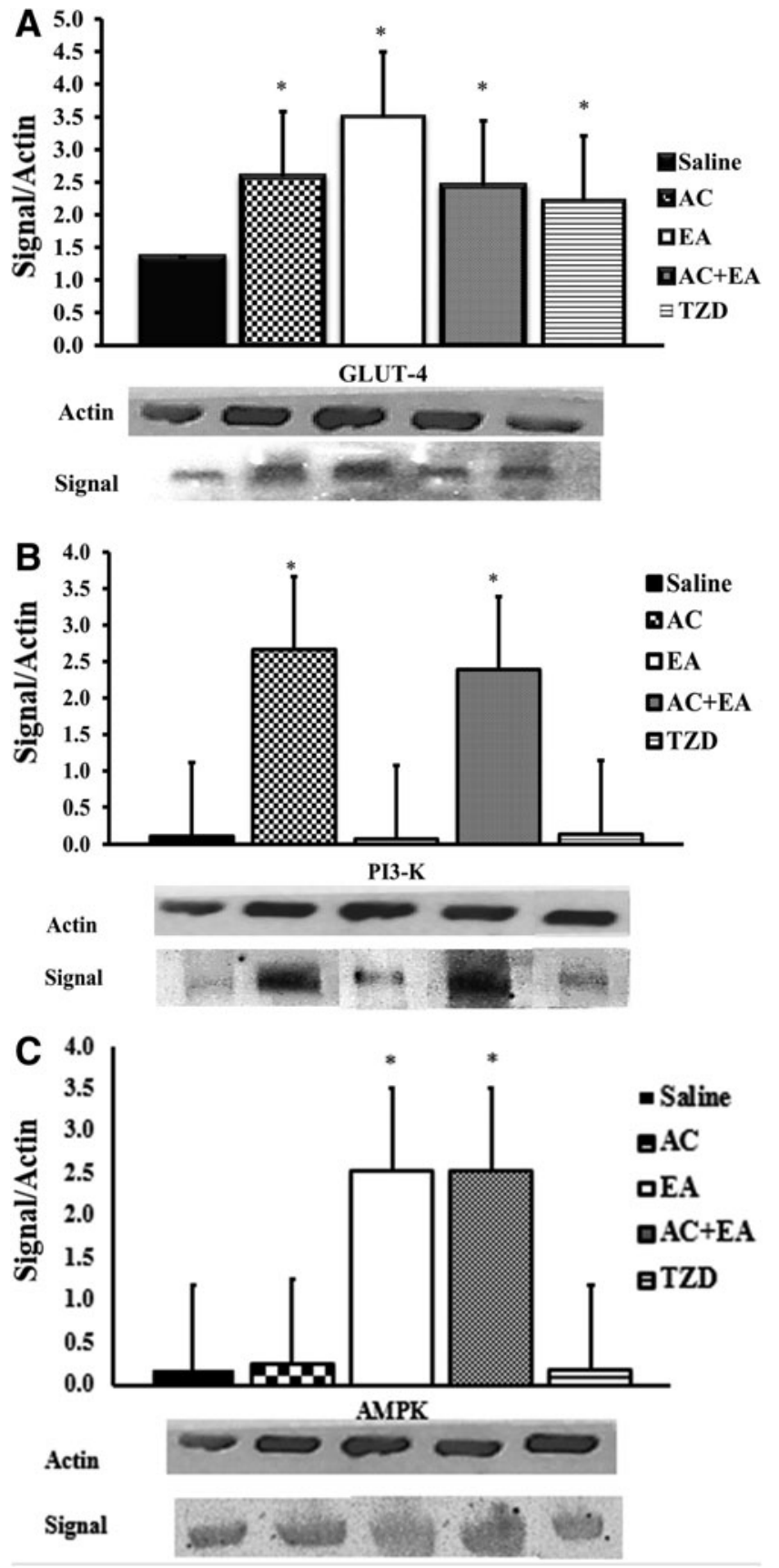

FIG. 3. The impact of electroacupuncture (EA) combined with Antrodia cinnamomea (AC; $500 \mathrm{mg} / \mathrm{kg}$ ) on the signaling proteins of steroid-induced insulin-resistant (SIIR) rats. (A) the expression levels of glucose transporter 4 (GLUT4). (B) the expression levels of phosphoinositide 3-kinase (PI3-K), (C) the expression levels of 5 ' adenosine monophosphate-activated protein kinase (AMPK). In the saline group, Wistar rats were administered normal saline. In the $\mathrm{AC}$ group, Wistar rats were administered oral $\mathrm{AC}$ extract $(500 \mathrm{mg} / \mathrm{kg})$. The EA group received normal saline and EA at ST $36(15 \mathrm{~Hz} / 10 \mathrm{~mA})$. The $\mathrm{AC}+\mathrm{EA}$ group received $\mathrm{AC}$ and $\mathrm{EA}$ as previously scheduled. The TZD (rosiglitazone) group received rosiglitazone $(0.1 \mathrm{mg} / \mathrm{kg}) ; * P<0.05$ versus saline. A Student's $t$-test was used to perform group analysis. significantly higher protein levels than the saline group. The level of the signal protein AMPK is presented in Figure 3C, where the EA and AC+EA groups had significantly higher AMPK protein than the saline group $(p<0.05)$. Significantly increased levels of insulin-signaling proteins (GLUT-4, AMPK, and PI3-K) were observed in the combined therapy group (AC+EA). In contrast, this was not observed for the single therapy (EA, AC, or TZD) same time.

\section{DISCUSSION}

One of the most common human diseases, diabetes mellitus, is caused by defects in insulin signaling. Insulin resistance is a chronic increase in insulin secretion, which overstimulates target cells in the liver and other parts of the body, leading to a chronic elevation in plasma glucose levels, which stimulates the pancreas to secrete more insulin. The two important downstream-signaling pathways are the Ras-Map kinase pathway and the insulin receptor-mediated cascade. Human bodies spend considerable effort maintaining plasma glucose levels within a narrow range. ${ }^{20}$

In this study, the rats' plasma-glucose levels after highdose steroid administration were significantly higher than those of normal rats. The rats injected with $1 \mathrm{mg} / \mathrm{kg}$ of dexamethasone for 5 days had significantly higher fasting plasma-glucose levels, compared to the nontreated rats. The SIIR rats treated with a chronic dose of dexamethasone could be a useful model to explore new therapies for addressing insulin resistance. ${ }^{2}$ The current study's results showed that EA, and AC+EA treatment improved the hypoglycemic effect significantly by reducing the plasmaglucose levels in the normal Wistar and SIIR rat models. This result was consistent with previous studies that showed the trend of hypoglycemia in rat models after treatment with $15-\mathrm{Hz}$ EA at bilateral ST 36 acupoints that confirmed the hypoglycemic effect. ${ }^{18,21}$

In the current authors' previous study, the experimental doses were determined in preliminary tests by administering various doses to SIIR rats to establish small, medium, and high doses $(100,200$, and $500 \mathrm{mg} / \mathrm{kg})$ appropriate for rats. This previous study showed that the optimal oral dose to achieve a hypoglycemic effect was $200 \mathrm{mg} / \mathrm{kg} \mathrm{AC}$. $^{3}$ A higher dose of AC $(500 \mathrm{mg} / \mathrm{kg})$ was chosen for the current this study for 2 reasons: (1) A single dose of AC $(500 \mathrm{mg} /$ $\mathrm{kg}$ ) had not been previously used to explore the mechanism of action. (2) The purpose of the current study was to identify a more-effective method other than EA or TZD signal therapy in diabetes treatment by elevating the expression of GLUT4, PI3-K, and AMPK signaling proteins.

The hypoglycemic pathway is speculated to be mediated by the phosphorylation of AMPK and the activation of PI3-K. The GLUT4 in the cell is activated and transferred to the cell membrane as a channel for glucose entry into the cell. 
Notably, the role of PI3-K is to activate a variety of signaling pathways. PI3-K provides the binding sites for Pleckstrin homology domain-containing signaling proteins, such as protein kinase $\mathrm{B}(\mathrm{PKB})$ and protein 3-phosphoinositide-dependent protein kinase-1. PKB regulates glucose uptake by GLUT4, which resides in the intracellular membrane vesicles tethered to the cis-Golgi network, through the cleaving of TUG in response to insulin. This allows the GLUT4 vesicles to fuse with the plasma membrane. ${ }^{20}$ Therefore, these 3 signaling proteins correlate with each other. The expression of the insulin signaling proteins, GLUT4, PI3-K, and AMPK, in insulin-resistant rats before and after each treatment was measured by Western blot. This study showed that the signal proteins (GLUT4, PI3-K, and AMPK) were enhanced better to perform their functions in the AC+EA treatment group. This seems better than single therapy at 60 minutes, increasing these 3 proteins than with the single therapy at the same time. Previous studies have indicated that AC stimulates AMPK and GLUT4 expression. ${ }^{3}$

Further exploration of the mechanism revealed that stimulation of synaptic vesicles could increase the release of acetylcholine, leading to an increase in insulin activity. The hypoglycemic mechanism is regulated through parasympathetic-nerve involvement. ${ }^{21}$ This study confirmed further that EA or AC+EA could reduce insulin resistance by lowering plasma-glucose levels. Studies have indicated that $\mathrm{AC}$ stimulates $\beta$-cells in the pancreas by peroxisome proliferator-activated receptor- $\gamma$, increases insulin secretion, restores the pancreas to its function, and reduces the symptoms of diabetes, leading to reduced complications. ${ }^{22}$ The change in HOMA-IR in SIIR rats was decreased by the AC+EA treatment, which was almost equal to the positive control TZD treatment, indicating an reduction of the insulin resistance induced by the combined therapy in 60 minutes. In addition, the results showed that the combination therapy might be better than the signal therapy (AC, EA, or TZD) according to the expression of signal-transduction proteins in this study. Further randomized controlled studies are needed to confirm the clinical hypoglycemic effect of the $\mathrm{AC}+\mathrm{EA}$ treatment.

\section{CONCLUSIONS}

This study demonstrated that SIIR rats had significantly reduced plasma glucose levels and insulin resistance by the EA combined with AC treatment. Likewise, the therapeutic effect was better than the EA, AC, or TZD therapies. The performance of signal proteins, GLUT4, AMPK, and PI3-K might be an important part of mechanisms in this EA combined with AC therapy to reduce hypoglycemic activity and insulin resistance. More research is needed to determine $\mathrm{EA}+\mathrm{AC}$ 's future role as a therapy for insulin resistance.

\section{AUTHOR DISCLOSURE STATEMENT}

No competing financial interests exist.

\section{FUNDING INFORMATION}

This study was supported by grants provided by the Ministry of Science and Technology (104-2632-E-212-001, 106-2622-E-212-002-CC2, and 108-2813-C-212-025-B), Taichung Veterans General Hospital, Changhua Christian Hospital, and Da-Yeh University Joint Project (TCVGHDYU-1088302, TCVGH-DYU-1098303, and CCH-DYUDMH-0717), in Taiwan.

\section{REFERENCES}

1. Naidu AS. Redox Life, 1st ed. Pomona, CA: Bio-Rep Media; 2013.

2. Tzeng CY, Lee YC, Chung JJ, et al. $15 \mathrm{~Hz}$ electroacupuncture at ST36 improves insulin sensitivity and reduces free fatty acid levels in rats with chronic dexamethasone-induced insulin resistance. Acupunct Med. 2016;34(4):296-301.

3. Chung YC, Tzeng CY, Chen YI, et al. Improving insulin resistance with Antrodia cinnamomea mycelium powder to induce a hypoglycemic effect in dexamethasone induced insulin resistant rats. Mol Med Rep. 2018;17(2):3260-3266.

4. Lu KH, Pan YC, Sheen LY. Combination of cut-log cultivated fruiting body and solid-state cultured mycelia of Taiwanofungus camphoratus ameliorates CCl4-induced liver injury in rats. J Tradit Complement Med. 2020;10(2): 166-174.

5. Huang YL, Chu YL, Ho CT, et al. Antcin K, an active triterpenoid from the fruiting bodies of basswood-cultivated Antrodia cinnamomea, inhibits metastasis via suppression of integrin-mediated adhesion, migration, and invasion in human hepatoma cells. J Agric Food Chem. 2015;63(18):4561-4569.

6. Wang G, Wan Y, Zhao J, Hong Z. Ethanol extract of Antrodia camphorata inhibits proliferation of HCT-8 human colorectal cancer cells by arresting cell cycle progression and inducing apoptosis. Mol Med Rep. 2017;16(4):4941-4947.

7. Li ZW, Kuang Y, Tang SN, et al. Hepatoprotective activities of Antrodia camphorata and its triterpenoid compounds against CCl4-induced liver injury in mice. J Ethnopharmacol. 2017;206:31-39.

8. Liu Y, Wang J, Li L, et al. Hepatoprotective effects of Antrodia cinnamomea: The modulation of oxidative stress signaling in a mouse model of alcohol-induced acute liver injury. Oxid Med Cell Longev. 2017;2017:7841823.

9. Chang YY, Liu YC, Kuo YH, et al. Effects of antrosterol from Antrodia camphorata submerged whole broth on lipid homeostasis, antioxidation, alcohol clearance, and anti-inflammation in livers of chronic-alcohol fed mice. J Ethnopharmacol. 2017; 202:200-207.

10. Shie PH, Wang SY, Lay HL, Huang GJ. 4,7-Dimethoxy-5methyl-1,3-benzodioxole from Antrodia camphorata inhibits LPS-induced inflammation via suppression of NF-kappa B 
and induction HO-1 in RAW264.7 cells. Int Immunopharmacol. 2016;31:186-194.

11. Chen YJ, Cheng PC, Lin CN, et al. Polysaccharides from Antrodia camphorata mycelia extracts possess immunomodulatory activity and inhibits infection of Schistosoma mansoni. Int Immunopharmacol. 2008;8(3):458-467.

12. Kumar KJ, Chu FH, Hsieh HW, et al. Antroquinonol from ethanolic extract of mycelium of Antrodia cinnamomea protects hepatic cells from ethanol-induced oxidative stress through Nrf-2 activation. J Ethnopharmacol. 2011;136(1): $168-177$.

13. Geethangili M, Tzeng YM. Review of pharmacological effects of Antrodia camphorata and its bioactive compounds. Evid Based Complement Alternat Med. 2011;2011:212641.

14. Lu ZM, Tao WY, Zou XL, Fu HZ, Ao ZH. Protective effects of mycelia of Antrodia camphorata and Armillariella tabescens in submerged culture against ethanol-induced hepatic toxicity in rats. J Ethnopharmacol. 2007;110(1):160-164.

15. Geng Y, Wang J, Sun Q, et al. Identification of antrodin B from Antrodia camphorata as a new anti-hepatofibrotic compound using a rapid cell screening method and biological evaluation. Hepatol Res. 2016;46(3):E15-E25.

16. Yu ML, Wei RD, Zhang T, et al. Electroacupuncture relieves pain and attenuates inflammation progression through inducing IL-10 production in CFA-induced mice. Inflammation. 2020;43(4):1233-1245.

17. Chen YI, Tzeng CY, Cheng YW, et al. The involvement of serotonin in the hypoglycemic effects produced by administration of the aqueous extract of Xylaria nigripes with steroid-induced insulin-resistant rats. Phytother Res. 2015;29(5):770-776.
18. Lin RT, Tzeng CY, Lee YC, et al. Acupoint-specific, frequency-dependent, and improved insulin sensitivity hypoglycemic effect of electroacupuncture applied to drugcombined therapy studied by a randomized control clinical trial. Evid Based Complement Alternat Med. 2014;2014: 371475.

19. Chang SL, Tsai CC, Lin JG, Hsieh CL, Lin RT, Cheng JT. Involvement of serotonin in the hypoglycemic response to $2 \mathrm{~Hz}$ electroacupuncture of Zusanli acupoint (ST36) in rats. Neurosci Lett. 2005;379(1):69-73.

20. Lodish HF. Molecular Cell Biology, 8th ed. New York: W.H. Freeman-Macmillan Learning; 2016.

21. Lee YC, Li TM, Tzeng CY, et al. Electroacupuncture at the Zusanli (ST-36) acupoint induces a hypoglycemic effect by stimulating the cholinergic nerve in a rat model of streptozotocine-induced insulin-dependent diabetes mellitus. Evid Based Complement Alternat Med. 2011;2011: 650263.

22. Vong CT, Tseng HH, Kwan YW, Lee SM, Hoi MP. Antrodia camphorata increases insulin secretion and protects from apoptosis in MIN6 cells. Front Pharmacol. 2016;7:67.

Address correspondence to: Shih-Liang Chang, MD, PhD

No. 168, University Road

Dacun, Changhua County 51591

Taiwan

E-mail: slc0124@gmail.com 